Full length article

\title{
The widening gender gap in marijuana use prevalence in the U.S. during a period of economic change, 2002-2014
}

\author{
Hannah Carliner ${ }^{\mathrm{a}}$, Pia M. Mauro ${ }^{\mathrm{a}}$, Qiana L. Brown ${ }^{\mathrm{a}}$, Dvora Shmulewitz ${ }^{\mathrm{b}, \mathrm{c}}$, \\ Reanne Rahim-Juwel $^{\mathrm{b}}$, Aaron L. Sarvet ${ }^{\mathrm{b}}$, Melanie M. Wall ${ }^{\mathrm{b}, \mathrm{c}, \mathrm{d}}$, Silvia S. Martins ${ }^{\mathrm{a}}$, \\ Geoffrey Carliner ${ }^{e}$, Deborah S. Hasin ${ }^{\mathrm{a}, \mathrm{b}, \mathrm{c}, *}$ \\ a Department of Epidemiology, Mailman School of Public Health, Columbia University, New York, NY, USA \\ ${ }^{\mathrm{b}}$ New York State Psychiatric Institute, New York, NY, USA \\ ${ }^{\mathrm{c}}$ Department of Psychiatry, College of Physicians and Surgeons, Columbia University, New York, NY, USA \\ d Department of Biostatistics, Mailman School of Public Health, Columbia University, New York, NY, USA \\ e Department of Economics, Boston University, Boston, MA, USA
}

\section{A R T I C L E I N F O}

\section{Article history:}

Received 25 April 2016

Received in revised form 19 October 2016

Accepted 22 October 2016

Available online 11 November 2016

\section{Keywords:}

Cannabis

Drug users

Men's health

Socioeconomic factors

Economic recession

\begin{abstract}
A B S T R A C T
Aim: Concurrently with increasingly permissive attitudes towards marijuana use and its legalization, the prevalence of marijuana use has increased in recent years in the U.S. Substance use is generally more prevalent in men than women, although for alcohol, the gender gap is narrowing. However, information is lacking on whether time trends in marijuana use differ by gender, or whether socioeconomic status in the context of the Great Recession may affect these changes.

Methods: Using repeated cross-sectional data from the National Survey on Drug Use and Health (2002-2014), we examined changes over time in prevalence of past-year marijuana use by gender, and whether gender differences varied across income levels. After empirically determining a change point in use in 2007, we used logistic regression to test interaction terms including time, gender, and income level.

Results: Prevalence of marijuana use increased for both men $(+4.0 \%)$ and women $(+2.7 \%)$ from 2002 to 2014 , with all of the increase occurring from 2007 to 2014. Increases were greater for men, leading to a widening of the gender gap over time $(p<0.001)$. This divergence occurred primarily due to increased prevalence among men in the lowest income level (+6.2\%) from 2007 to 2014.

Conclusion: Our findings are consistent with other studies documenting increased substance use during times of economic insecurity, especially among men. Corresponding with the Great Recession and lower employment rate beginning in 2007, low-income men showed the greatest increases in marijuana use during this period, leading to a widening of the gender gap in prevalence of marijuana use over time.
\end{abstract}

(c) 2016 Published by Elsevier Ireland Ltd.

\section{Introduction}

Among individuals aged 12 and older in the U.S. in 2014, 8.4\% reported past-month and $12.5 \%$ reported past-year marijuana use (CBHSQ 2015; SAMHSA, 2014). Attitudes about the risks of marijuana use are changing (Pacek et al., 2015), and prevalence of use has increased since 2001 (Grucza et al., 2016; Hasin et al., 2015; SAMHSA, 2003, 2014). With marijuana currently legalized for medical use in 28 states, and recreational use in eight of these, permissive attitudes towards marijuana use are becoming more

\footnotetext{
* Corresponding author at: Department of Psychiatry, Columbia University Medical Center, 1051 Riverside Drive \#123, New York, NY 10032, USA

E-mail address: deborah.hasin@gmail.com (D.S. Hasin).
}

prevalent, with further increases in use anticipated (Pew Research Center, 2014). As the social and legal environment surrounding marijuana use changes, a more nuanced understanding of adult trends in marijuana use by population subgroups is an important public health issue.

Increased marijuana use among adults could have adverse consequences, e.g., marijuana use disorders (Hall and Degenhardt, 2009; Hasin et al., 2015; Volkow et al., 2014), respiratory diseases (Hall, 2009; Tashkin et al., 2002), lower educational and career achievement (Fergusson and Boden, 2008; Henkel, 2011), and vehicular crashes (Hall and Degenhardt, 2009; Li et al., 2012; Volkow et al., 2014). Potentially beneficial consequences, e.g., decreased opioid use and mortality (Bachhuber et al., 2014; Kim et al., 2016, 2015; Powell et al., 2015), and decreased traffic fatalities (Anderson et al., 2013) could also occur. Thus, assessing 
population-level change in marijuana use over time, particularly by sociodemographic characteristics, may help identify population subgroups most likely to increase marijuana use, enabling public health practitioners to plan targeted interventions for these changes.

While the prevalence of substance use consistently varies between men and women (SAMHSA, 2003, 2014), the gender gap in prevalence of use of a given substance is not necessarily stable over time. At the population level, gender-specific changes in use could translate into millions of people at increased risk for marijuana-related outcomes over time. Identifying trends in use by gender is therefore valuable for public health planning and targeting interventions. While men historically report higher prevalence of drinking than women, this gender gap has narrowed in recent years (Keyes et al., 2008, 2011; McHugh et al., 2014; White et al., 2015), a change attributed to increasing gender equality in social roles, and to changes in social norms regarding acceptability of drinking by women. In contrast, a review found that the gender gap in cigarette smoking remained largely unchanged between 2004 and 2014, with a stable male to female prevalence ratio of about 1.3:1 (Higgins et al., 2015). Studies of past-year marijuana use have also documented that temporal changes in prevalence vary by gender. For example, between 1984 and 2000, prevalence among young men decreased from $33 \%$ to $22 \%$ yet increased among young women from $12 \%$ to $19 \%$, resulting in a substantial narrowing of the gender gap in marijuana use (Kerr et al., 2007). Other studies have suggested a slight increase in the gender gap in marijuana use since 2002, but did not formally test for gender differences in trends using the most recent annual prevalence estimates (Pacek et al., 2015). In sum, no current information exists specifically testing whether time trends in the prevalence of marijuana use differ by gender.

In addition, whether patterns in marijuana use by gender are consistent across income levels is unknown, which is particularly relevant during economic downturns. Unlike some sociodemographic characteristics, individual income can vary over time. As a potentially modifiable risk factor, identifying a role for income in marijuana use trends could inform public health policy and prevention and also provide insight into drivers of change in marijuana use. Studies show that socioeconomic status can modify the association between gender and alcohol use among adults (Arcaya et al., 2014; Vijayasiri et al., 2012) and between gender and marijuana use among adolescents and young adults (Hanson and Chen, 2007; Miller and Miller, 1997; Pitel et al., 2013). Other studies report that socioeconomic changes, e.g., unemployment, are associated with increased use of marijuana (Arkes, 2007; Merline et al., 2004). Substantial changes in the U.S. economy occurred in recent years, beginning with the Great Recession (Business Cycle Dating Committee of the National Bureau of Economic Research, 2008) and increased unemployment rate (U.S. Bureau of Labor Statistics, 2016); and continuing with high income inequality, low labor force participation, and continued declines in median real earnings (Acs, 2011; Greenstone and Looney, 2011a, 2013; Kearney et al., 2015). These macroeconomic changes are associated with changes in substance use among both men and women (Arcaya et al., 2014; Bor et al., 2013; Case and Deaton, 2015; Catalano et al., 2011; Tekin et al., 2013). However, the joint effect of gender and socioeconomic status on marijuana use among adults over time has not been examined, even though marijuana is one of the most widely used psychoactive substances (SAMHSA, 2014).

We therefore examined gender differences in the prevalence of marijuana use and whether such differences are changing over time, using data from the 2002-2014 U.S. National Survey on Drug Use and Health (NSDUH) adult sample. We further assessed whether any differences varied by income level. First, we assessed whether national estimates of prevalence of past-year marijuana use were linear over time, or whether any distinct change point in trends occurred. Second, we tested whether time trends in marijuana use were the same for men and women. Third, we assessed whether gender differences in changes in prevalence of marijuana use over time were modified by household income level.

\section{Methods}

\subsection{Sample and procedures}

The NSDUH provides annual cross-sectional national survey data on substance use in a sample of the U.S. population over age 12, living in households and non-institutional group quarters. Sponsored by the Substance Abuse and Mental Health Services Administration (SAMHSA), the survey uses a multistage area probability sample for all 50 states and the District of Columbia. Younger individuals, Blacks, and Hispanics were oversampled. Response rates range from 71 to $79 \%$ over the years studied (CBHSQ 2015; SAMHSA, 2003). The NSDUH surveys were methodologically consistent between 2002 and 2014, and therefore these were the years we examined.

Trained interviewers administered the survey using computerassisted personal interviewing (CAPI), supplemented by audio computer-assisted self-interviewing (ACASI), in order to provide participants with privacy and confidentiality when responding to questions about illicit drug use and other sensitive behaviors (CBHSQ 2015; SAMHSA, 2003). Participants gave informed consent prior to being interviewed. Additional details on data confidentiality maintenance are provided elsewhere (CBHSQ 2015; SAMHSA, 2003). Our analyses utilized de-identified publicly available data, exempt from Institutional Review Board approval. Datasets from each year were concatenated, adding a variable for survey year. Adults (ages $18+$ ) were included $(\mathrm{N}=492,831)$. NSDUH sampling weights were used to adjust for non-response and oversampling, to correspond to population estimates from the U.S. Census Bureau.

\subsection{Measures}

Past-year marijuana users were defined as participants who reported most recent marijuana use "within the past 30 days" or "more than 30 days ago but within the past 12 months." Adjusted models included these covariates: race/ethnicity (Hispanic, nonHispanic Black, non-Hispanic Other, non-Hispanic White), age (18-25, 26-34, 35+), education level (less than high school, high school, at least some college), household income (\$0-19,999, $\$ 20,000-49,999, \$ 50,000-74,999, \$ 75,000+)$, and marital status (married, previously married, never married).

\subsection{Statistical analysis}

2.3.1. Trends in use over time. To test trends in past-year marijuana use over time, the outcome was regressed on a variable indicating interview year (2002-2014, continuous), using logistic regression. The regression coefficient for the year variable indicates the slope (change over time) on the multiplicative (log-odds) scale. To evaluate change over time in prevalence of use, we back-transformed model-predicted marginal log-odds of past-year marijuana use to the prevalence scale (Bieler et al., 2010); the difference in the prevalence for the last year as compared to the first year (risk difference) indicates the change over time for the entire time period.

To determine if the change over time differed by gender, an interaction term between year and gender was included in the regression model, and an interaction contrast (IC) was evaluated (Rothman et al., 2008). The IC estimates a "difference in differences" or the difference in the prevalence differences (from the last 
year as compared to the first year) for men versus women. Wald $t$ tests assessed the statistical significance of the risk differences and ICs. Trend analyses were carried out unadjusted and adjusted for sociodemographic variables.

2.3.2. Piecewise regression to identify change point. We conducted piecewise logistic regression (Schwarz, 2015; Toms and Lesperance, 2003) to determine if the rate of change (slope) in the log-odds of past-year marijuana use was similar over the whole time period (2002-2014), or if there was a year at which the slope changed (knot). Without a priori justification for assigning a specific year as the knot, an iterative grid-search algorithm was used (Ertel and Fowlkes, 1976; Muggeo, 2003) where each year was tested as a potential knot, i.e. a point at which the slope from that year forward was significantly different from the slope for the previous years. Specifically, a separate piecewise logistic regression model, $\operatorname{logit}(\operatorname{Pr}($ marijuana use $))=\beta_{0}+\beta_{1}{ }^{*}$ year $+\beta_{2}{ }^{*}(\text { year }-C)^{+}$, was fit for each potential knot year $C=2003$ to 2013 where $(\text { year }-C)^{+}$ takes the value 0 if the argument is negative (i.e. the year is earlier than $\mathrm{C}$ ) and the value of the argument if it is positive. The regression coefficient $\beta_{2}$ indicates the change in slope from the knot until 2014. The best fitting change point was determined based on the model with the highest R-squared value (i.e. smallest mean squared error), where a model with no change point was also included for comparison. Analyses were carried out unadjusted and adjusted for sociodemographic variables, to ensure that sociodemographics were not influencing the choice of the knot year.

Based on results showing that the best-fitting trend model in marijuana use in the whole population had a change point in 2007 (Table S2; adjusted R-squared value for $2007=0.10739$ ), regression models examining overall trends and differences by gender were evaluated separately for 2002-2007 and 2007-2014 (to account for potentially different trends) Using 2007 as the endpoint for the earlier part of the period and the start-point of the latter period provided continuous information across the entire time period (Fig. 1). When combining data over years, new sample weights were created by dividing the original weight by the number of datasets combined, based on SAMHSA recommendations (SAMHSA, 2014), following procedures used previously (Pacek et al., 2015). Models were evaluated unadjusted, and adjusted for sociodemographic covariates including age, race/ethnicity, income, education, marital status, and gender (for analyses of the full sample).

2.3.3. Trends in use over time, by gender and income level. Because results indicated that men showed a greater increase in prevalence of marijuana use than women over the period 2007-2014, we used a three-way interaction term (year, gender, income) in the regression models to test if the gender difference in rate of change varied by income. These models also included all possible two-way interactions between the three variables. The three-way interaction contrasts estimated the change over the time period for men versus women for each category of income, versus the reference income category ( $\geq \$ 75,000$ ). Wald $t$-tests were used to assess the statistical significance of the three-way ICs.

Sensitivity analyses also assessed whether trends were consistent by frequency of use, distinguishing individuals reporting daily past-year marijuana use (use 300 or more days in the past year) and non-daily past-year marijuana use (use less than 300 days in the past year). All analyses were conducted using SUDAAN 11.0.1, adjusting for the complex survey design of the NSDUH.

\section{Results}

Across all years, about half of the population was female, married, had an annual household income $\geq \$ 50,000$, and had greater than a high school educational level. About two-thirds were nonHispanic White and about one-third were younger than age 35 (Table S1). Sample characteristics were similar for men and women, except that more women were previously married while more men were never married.

\subsection{Marijuana use in men and women}

Prevalence of past-year marijuana use remained relatively stable between 2002 and 2007, followed by an increase in use between 2007 and 2014 (Fig. 1). At all time points, prevalence of pastyear marijuana use was higher among men than women (Table 1 ). Between 2002 and 2007, prevalence of past-year marijuana use remained stable for men and decreased slightly, albeit significantly, for women. However, no significant gender difference in differences was found in adjusted models (Table 1). Between 2007 and 2014, prevalence of marijuana use increased among men from $13.0 \%$ to $17.4 \%(+4.4 \%)$ and among women from $7.2 \%$ to $10.0 \%$ $(+2.7 \%)$, with the increase significantly greater among men, leading to a widening of the gender gap in marijuana use over time $(p=0.0001)$. This difference persisted when assessing the entire period from 2002 to 2014 as a whole, with marijuana use increasing for both men and women, but with a greater increase among men (Table 1). Tests for the additive interaction of gender by time indicated that the increase in prevalence of marijuana use was significantly greater for men than women $(p=0.0001)$. Fig. 2 illustrates the changes in prevalence estimates overall and in men and women separately for the two time periods, 2002-2007 and 2007-2014.

\subsection{Marijuana use in men and women by income level}

Considering the period 2007-2014, the prevalence of marijuana use increased significantly among men and women at all four income levels in both unadjusted (Table S3) and adjusted (Table 2) models. Among men and women in households with the two highest annual income levels, this increased prevalence was of similar magnitude by gender. However, in households with the two lowest income levels, the increased prevalence of marijuana use was greater among men than women (3.7\% higher and $2.3 \%$ higher respectively; Table 2). Compared to participants with annual household incomes greater than $\$ 75,000$, the gender gap increased by $3.1 \%$ in individuals at the lowest level of income from 2007 to 2014 , a statistically significant three-way interaction of gender by income by time $(p=0.018)$. This is equivalent to an increased prevalence of $6.2 \%$ among men and $2.5 \%$ among women with annual incomes $<\$ 20,000$.

\subsection{Sensitivity analyses for daily and non-daily past-year marijuana use}

Overall, results for the three time periods were substantively the same as reported above when assessing daily marijuana users and non-daily marijuana users (Table S4). Results were consistent across gender and income levels, though some statistical interaction tests only trended towards significance, given the smaller sample size in the stratified analyses.

\section{Discussion}

In successive annual surveys providing nationally representative samples of the U.S. non-institutionalized adult population, the prevalence of marijuana use increased for both men and women between 2002 and 2014. In 2002, approximately 12.4 million men (13.4\%) and 7.7 million women (7.7\%) used marijuana in the past year. By 2014 , these numbers had grown to approximately 18.4 million men (16.9\%) and 11.7 million women (10.1\%), an increase 


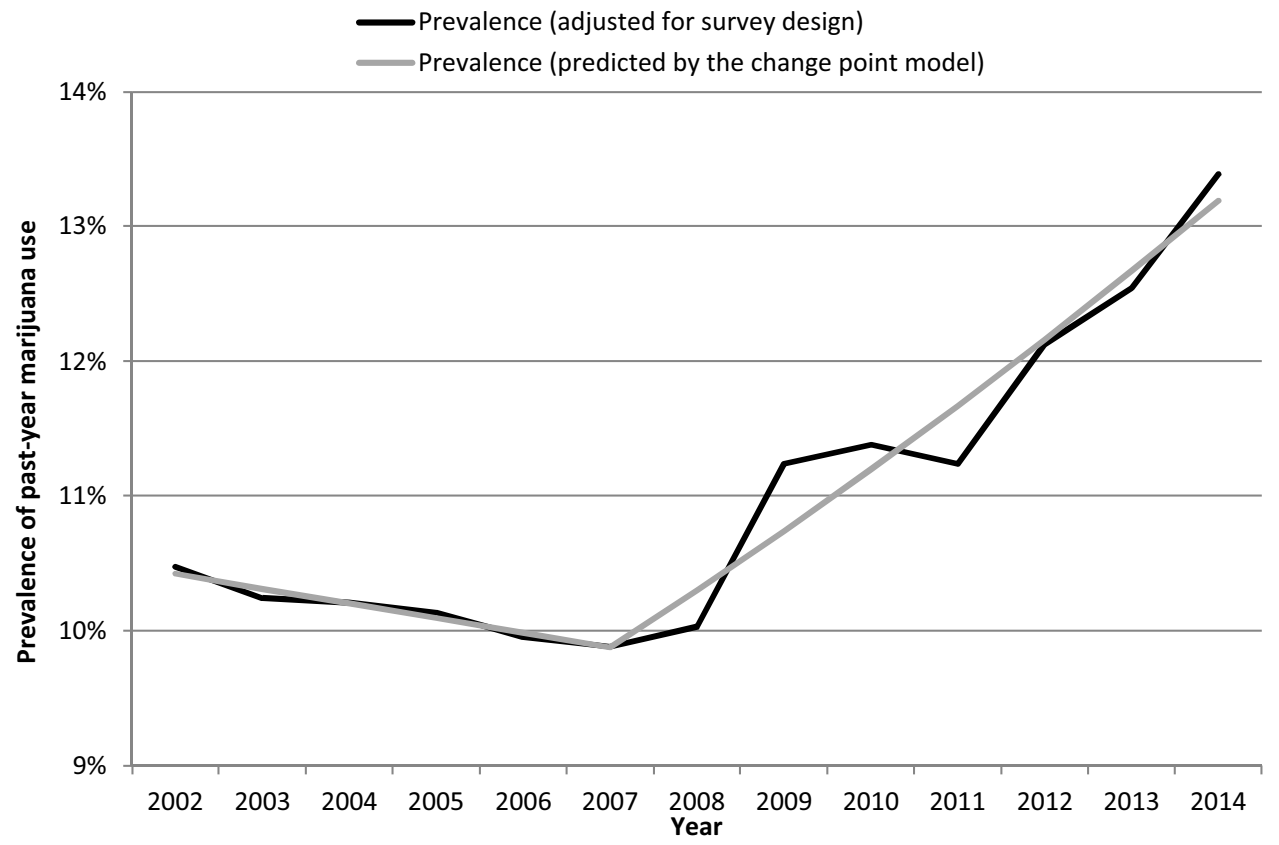

Fig. 1. Change point model of prevalence of past-year marijuana use, NSDUH years 2002-2014 $(\mathrm{N}=492,831)$.

Predicted prevalence is from the piecewise regression model allowing for one slope from 2002 until 2007, and a second slope from 2007 to 2014

Table 1

Trends in the prevalence of past-year marijuana use, overall and by gender, NSDUH $(\mathrm{N}=492,831)^{\mathrm{a}}$.

\begin{tabular}{|c|c|c|c|c|c|c|}
\hline & 2002 & $\begin{array}{l}\text { Change in prevalence }{ }^{\mathrm{b}} \\
2002-2007 \\
\%(\mathrm{SE}), p \text {-value }\end{array}$ & 2007 & $\begin{array}{l}\text { Change in prevalence }{ }^{\text {b }} \\
\text { 2007-2014\% (SE), } p \text {-value }\end{array}$ & 2014 & $\begin{array}{l}\text { Change in prevalence }{ }^{\mathrm{b}} \\
2002-2014 \% \text { (SE), } p \text {-value }\end{array}$ \\
\hline Total & $\begin{array}{l}10.47 \% \\
(0.28)\end{array}$ & $\begin{array}{l}-0.40 \%(0.26) \\
p=0.13\end{array}$ & $\begin{array}{l}9.88 \% \\
(0.24)\end{array}$ & $\begin{array}{l}+3.54 \%(0.22) \\
\mathrm{p} \leq 0.0001\end{array}$ & $\begin{array}{l}13.39 \% \\
(0.18)\end{array}$ & $\begin{array}{l}+3.31 \%(0.19) \\
\mathrm{p} \leq 0.0001\end{array}$ \\
\hline Men & $\begin{array}{l}13.43 \% \\
(0.44)\end{array}$ & $\begin{array}{l}-0.24 \%(0.39) \\
p=0.55\end{array}$ & $\begin{array}{l}12.86 \% \\
(0.38)\end{array}$ & $\begin{array}{l}+4.44 \%(0.34) \\
\mathrm{p} \leq 0.0001\end{array}$ & $\begin{array}{l}16.92 \% \\
(0.33)\end{array}$ & $\begin{array}{l}+4.00 \%(0.30) \\
\mathrm{p} \leq 0.0001\end{array}$ \\
\hline Women & $\begin{array}{l}7.74 \% \\
(0.27)\end{array}$ & $\begin{array}{l}-0.56 \%(0.26) \\
p=0.03\end{array}$ & $\begin{array}{l}7.10 \% \\
(0.24)\end{array}$ & $\begin{array}{l}+2.69 \%(0.29) \\
\mathrm{p} \leq 0.0001\end{array}$ & $\begin{array}{l}10.11 \% \\
(0.25)\end{array}$ & $\begin{array}{l}+2.66 \%(0.20) \\
\mathrm{p} \leq 0.0001\end{array}$ \\
\hline $\begin{array}{l}\text { Difference in change in } \\
\text { prevalence } \\
\text { men vs women }^{c}\end{array}$ & & $\begin{array}{l}0.33 \%(0.41) \\
p=0.42\end{array}$ & & $\begin{array}{l}1.74 \%(0.45) \\
p \leq 0.0001\end{array}$ & & $\begin{array}{l}1.35 \%(0.34) \\
p \leq 0.0001\end{array}$ \\
\hline
\end{tabular}

men vs women

Covariates in adjusted analyses include age, race/ethnicity, income, education, marital status; gender also included for analysis in the whole set.

a Adjusted for complex survey design.

b "Change in prevalence" refers to the difference in the estimated prevalences for the end-points of the time period: prevalence in 2014 minus prevalence in 2002 ;

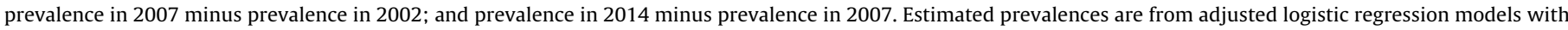

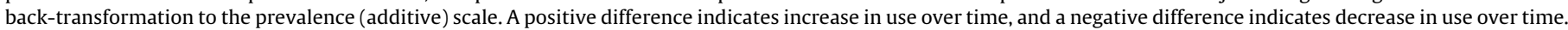

c Difference in change in prevalence (over time) for men versus women, also known as an interaction contrast. A difference that is significantly different from zero indicates additive interaction, i.e., different changes over time in men versus women.

of 3.5\% (6 million men) and 2.4\% (4 million women) respectively, for an estimated total of 10 million additional Americans using marijuana in 2014 compared to 2002.

We identified a change point in marijuana use trends in 2007 in the full sample, after which the prevalence of use sharply increased. This points to the importance of modeling non-linear trends in changes in substance use over time to identify temporal factors associated with these changes. These results replicate the findings of another recent study using NSDUH data which also identified 2007 as a change point using different statistical methods (Compton et al., 2016a). The increase in marijuana use prevalence may be explained by several factors. One is that the national increases in marijuana use prevalence reported here parallel legalization of medical and recreational marijuana use across the U.S., as recent studies have shown that legalization is associated with increases in past-year marijuana use among adults (Pacula et al., 2013; Wen et al., 2014). In 2002, 19\% of the U.S. population lived in a state with legalized medical marijuana use (ProCon.org, 2016;
U.S. Census Bureau, 2010). This proportion remained relatively unchanged through 2007 (i.e., 20.6\% of the population). Because several large states passed medical marijuana laws in 2008 and the years following, this number had more than doubled by 2014 to include $47 \%$ of the U.S. population. Access to medical marijuana and perceptions of normalization of use may have contributed to the increase in use during this time period (Martins et al., 2016). However, many people are not aware of the criminal status of marijuana use in the states in which they live, implying that changing laws may have little immediate effect on individuals' decisions to use (MacCoun et al., 2009).

Other explanations for the change in trends in marijuana use may relate to similar changes in opioid and heroin use beginning in 2007 (Compton et al., 2016b; Meiman et al., 2015), and the introduction of e-cigarettes in 2007, which can be used for marijuana consumption and which may have altered perceptions of risk or made consumption accessible to a wider range of people (Budney et al., 2015; Lee et al., 2016; Noel et al., 2011). The national trend 


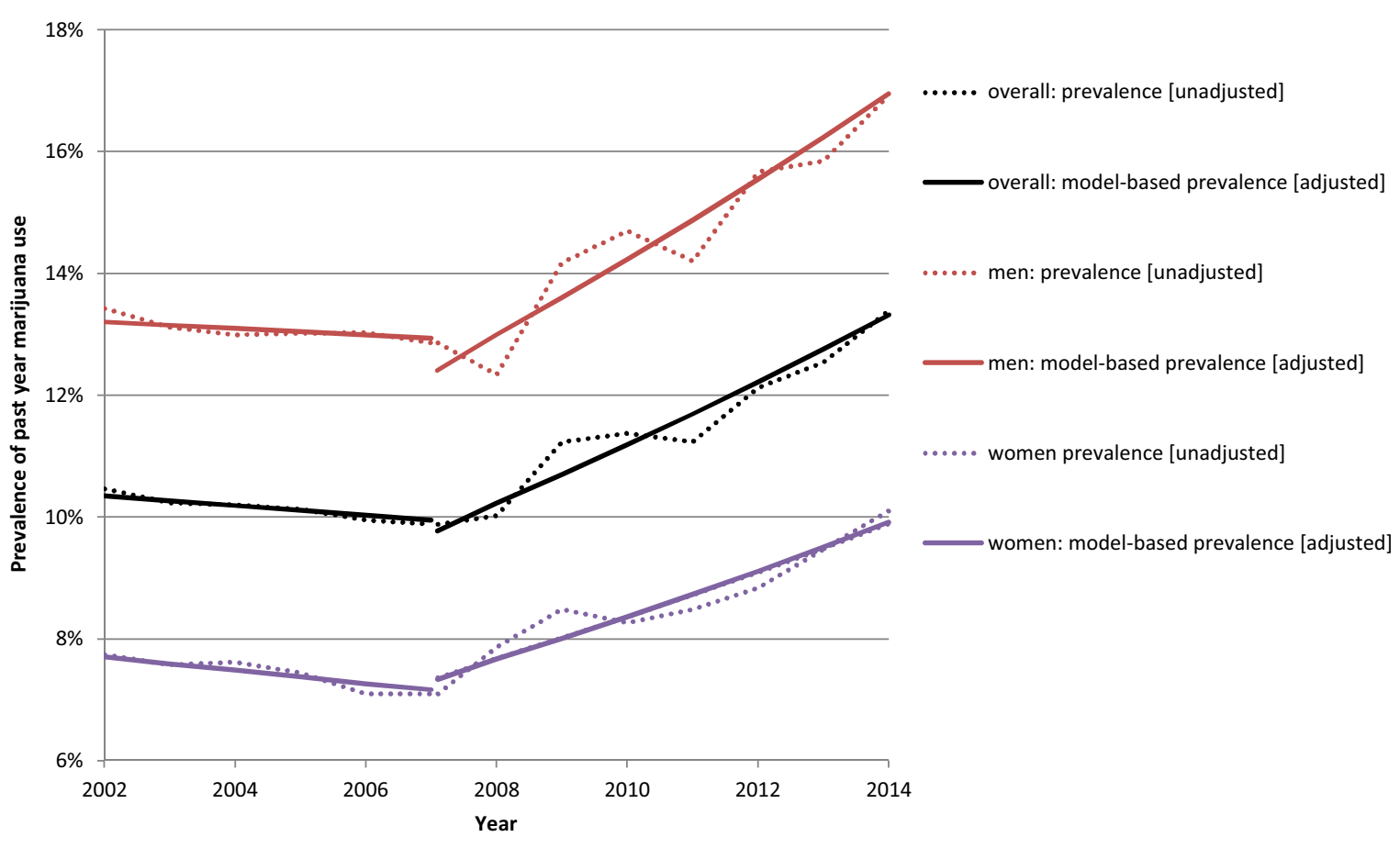

Fig. 2. Change in prevalence of past-year marijuana use overall and by gender, for 2002-2007 and 2007-2014.

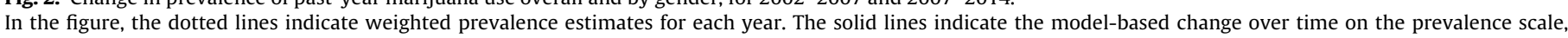

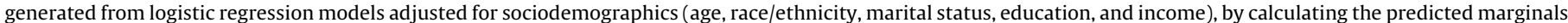

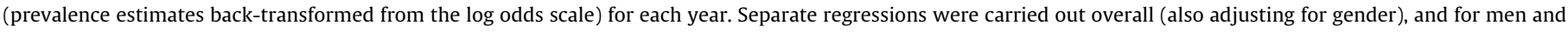
women.

Table 2

Differential trends in prevalence of past-year marijuana use by gender, by income, NSDUH 2007-2014 $(\mathrm{N}=307,935)^{\mathrm{a}}$.

\begin{tabular}{|c|c|c|c|c|c|c|}
\hline \multirow[b]{2}{*}{ Household income } & \multirow[b]{2}{*}{ Gender } & \multicolumn{2}{|c|}{ Weighted prevalence } & \multicolumn{3}{|l|}{ Adjusted for covariates ${ }^{\mathrm{b}}$} \\
\hline & & 2007 & 2014 & $\begin{array}{l}\text { Change in prevalence } \\
(\mathrm{SE}), \mathrm{p} \text {-value }\end{array}$ & $\begin{array}{l}\text { Difference in change in } \\
\text { prevalence } \\
\text { men vs. women }^{\text {d }} \\
\text { (SE), p-value }\end{array}$ & $\begin{array}{l}\text { Differences by } \\
\text { income level }^{\mathrm{e}} \\
\text { (SE), p-value }\end{array}$ \\
\hline \multirow[t]{2}{*}{$\$ 0-19,999$} & Men & $18.82 \%(0.58)$ & $26.11 \%(0.83)$ & $6.15 \%(0.85), \leq 0.0001$ & $3.70 \%$ (0.98), 0.0002 & $3.10 \%$ (1.30), 0.018 \\
\hline & Women & $10.81 \%(0.45)$ & $13.89 \%(0.47)$ & $2.46 \%(0.60), \leq 0.0001$ & reference & \\
\hline \multirow[t]{2}{*}{$\$ 20,000-49,999$} & Men & $13.09 \%(0.37)$ & $17.65 \%(0.49)$ & $4.62 \%(0.65), \leq 0.0001$ & $2.30 \%(0.81), 0.005$ & $1.71 \%(1.24), 0.17$ \\
\hline & Women & $7.40 \%(0.23)$ & $9.62 \%(0.29)$ & $2.32 \%(0.43), \leq 0.0001$ & reference & \\
\hline \multirow[t]{2}{*}{$\$ 50,000-74,999$} & Men & $11.29 \%(0.49)$ & $14.18 \%(0.55)$ & $3.25 \%(0.85), 0.0002$ & $0.33 \%$ (1.17), 0.78 & $-0.26 \%$ (1.37), 0.85 \\
\hline & Women & $6.03 \%(0.33)$ & $8.46 \%(0.41)$ & $2.92 \%(0.65), \leq 0.0001$ & reference & \\
\hline \multirow[t]{2}{*}{$\$ 75,000+$} & Men & $9.88 \%(0.37)$ & $12.93 \%(0.36)$ & $3.84 \%(0.64), \leq 0.0001$ & $0.59 \%(0.86), 0.49$ & reference \\
\hline & Women & $5.70 \%(0.31)$ & $8.21 \%(0.31)$ & $3.25 \%(0.58), \leq 0.0001$ & reference & \\
\hline
\end{tabular}

a Adjusted for complex survey design.

b Covariates include age, race/ethnicity, and marital status.

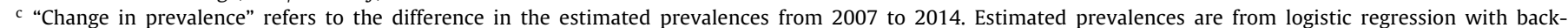
transformation to the prevalence (additive) scale. A positive difference indicates increase in use over time.

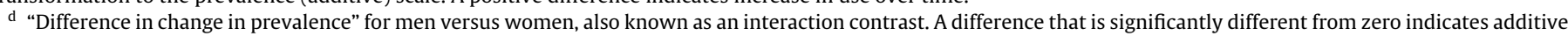
interaction, i.e., different changes in men versus women.

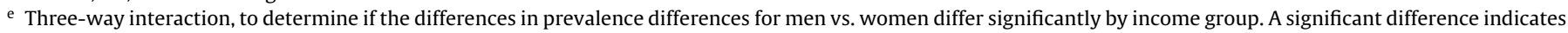
that the relationship between men and women differs by income group.

data reported here cannot answer such questions, however they provide a basis for additional research to address these explanations using different study designs.

Contrary to past trends indicating a narrowing of the gender gap in marijuana use between 1984 and 2000, driven largely by decreased use by men (Kerr et al., 2007), we found that prevalence of marijuana use increased for both men and women between 2007 and 2014 , but more for men, leading to a widening of this gender gap. This confirms and provides a formal test of trend of observed recent increases in marijuana use reported previously(Pacek et al., 2015). Sensitivity analyses highlight that these changes occurred among daily and non-daily marijuana users, paralleling findings from another recent NSDUH study showing that both initiation of marijuana use and daily use increased between 2002 and 2014 (Compton et al., 2016a). Thus, the increases are not only due to more individuals trying marijuana due to changing laws and attitudes, but also an increase in individuals using marijuana daily, especially among low income men. Daily users may be at particularly high risk for marijuana use disorders and some may be at risk of using other drugs (Hall and Degenhardt, 2009; Hasin et al., 2016; Stinson et al., 2006). Alternatively, increased marijuana use could be evidence of a substitution effect for marijuana over other drugs or alcohol (Anderson et al., 2013; Crost and Guerrero, 2012; Guttmannova et al., 2016; Kim et al., 2016). Increased use does not necessarily 
indicate increases in problematic use or treatment seeking (Hasin et al., 2015; Maxwell and Mendelson, 2016). Future work should track individual changes in these substance use patterns over time, in relation to social and economic changes.

These results contrast the narrowing gender gap in alcohol use in recent years (Keyes et al., 2008, 2011; McHugh et al., 2014; White et al., 2015). Our findings suggest that different mechanisms may operate for gendered patterns in marijuana use. While prevalence of past-month alcohol use has been stable or decreasing among U.S. men since 2002, prevalence has generally been rising among women of legal drinking age (White et al., 2015). Taken together, more men and more women are using marijuana now than a decade ago, while only more women are using alcohol.

Many factors, including social norms, propensity for risk-taking, and perceived risk of marijuana use (Byrnes et al., 1999; Pacek et al., 2015; Ronay and Kim, 2006), may explain the historical gender gap in marijuana use, but they do not explain the increase in this gap beginning in 2007 . Similarly, factors such as more permissive attitudes, increased use for medical reasons, fewer legal ramifications, and increased availability of marijuana (Cerdá et al., 2012; Grucza et al., 2016; Hasin et al., 2015; Pacek et al., 2015) may contribute to the overall increase in use, as also noted elsewhere (Compton et al., 2016a; Grucza et al., 2016; Hasin et al., 2015; Substance Abuse and Mental Health Services Administration, 2003, 2014). However, none of these explanations address the reasons this increase would be greater in men than women, and why this trend would sharply change after 2007. Without longitudinal data, we cannot determine with certainty which factors are responsible for these changes in marijuana use in U.S. men and women. However, we further investigated these trends by examining differences by income level over the 2002-2014 period to explore whether economic forces appeared to have contributed to these patterns.

Stratified analyses and tests of statistical interaction showed that the gender gap in marijuana use prevalence only increased in households earning less than $\$ 50,000$ annually. Men at the lowest income levels reported the greatest increases in marijuana use (+6.2\%) between 2007 and 2014, even after controlling for sociodemographic differences in income strata. This corresponds with national economic trends including the beginning of the Great Recession (Business Cycle Dating Committee of the National Bureau of Economic Research, 2008) and rise in the unemployment rate beginning in 2007 (U.S. Bureau of Labor Statistics, 2016). Because coping with stress is often considered a motive for marijuana use (Buckner et al., 2007; Bujarski et al., 2012; Simons et al., 2000), financial hardship and economic insecurity related to the weak national economy could have contributed to this increased prevalence nationally, particularly for low-income men (Case and Deaton, 2015; Meara and Skinner, 2015).

The Great Recession created the largest number of long-term unemployed since records have been kept in the U.S., increasing the proportion of Americans living in poverty (Seefeldt et al., 2012). Particularly in the predominantly male manufacturing and construction sectors, employment rates remain lower than they were at the start of the recession, contributing to the growth of wage inequality in the U.S. (Evangelist and Bernhardt, 2014; Schmitt and Jones, 2012). While an economic "recovery" in terms of job growth, median household income, and long-term unemployment began around 2012, it largely bypassed this segment of the population, among whom the employment rate and median real earnings remain low (Acs, 2011; Greenstone and Looney, 2011b, 2013; Kearney et al., 2015).

Qualitative studies have found that men are more likely to define their self-identity based on their work role (Cinamon, 2002; Ford, 2007). Men in traditional gender roles who are affected by labor market transformations may therefore be more likely to use drugs as a form of avoidant coping (Moos, 2007; Taylor and Stanton,
2007; Wills and Shiffman, 1985), related to lowered self-esteem, depression, and lack of opportunities (Forret et al., 2010; McKeeRyan et al., 2005; Sherman, 2009). While this interpretation of the current study results is speculative, the consistency in findings across quantitative and qualitative methodologies supports continued research regarding the effects of macroeconomic changes on individual coping behavior and substance use patterns.

Our findings are consistent with studies documenting increased mortality among middle-aged low socioeconomic status U.S. Whites since 1998 , primarily due to external causes such as drug and alcohol poisoning (Case and Deaton, 2015). We add to this body of evidence by showing that prevalence of marijuana use may also be changing among low income Americans, particularly men. Reducing marijuana use could be an important clinical target for preventing the serious morbidity and mortality associated with excessive use of marijuana - alone or in combination with other harmful substances. Focused studies are needed to provide empirical evidence of changes in marijuana use over time for men and women in response to economic insecurity.

Job loss, unemployment, and poor future economic prospects are associated with changes in tobacco and alcohol consumption, especially among men (Arcaya et al., 2014; Bor et al., 2013; Brainerd and Cutler, 2004; Catalano et al., 1993; Henkel, 2011; Mossakowski, 2008; Vijayasiri et al., 2012). Additionally, recent unemployment is associated with higher odds of past-month marijuana use among adults (Merline et al., 2004) and state unemployment rates are associated with higher adolescent marijuana use (Arkes, 2007). Our cross-sectional data show national trends by gender and income, rather than individual behavior change. However, the results for men in the lowest income level are consistent with previous findings for alcohol, tobacco, and marijuana, both by gender and in support of hypotheses regarding substance use being a form of coping with the stress and disempowerment associated with financial hardship (Brainerd and Cutler, 2004; Henkel, 2011; McKee-Ryan et al., 2005).

\subsection{Limitations}

Study limitations are noted. First, the NSDUH relies on selfreported substance use, which may be subject to bias due to its historically illicit status and the government-sponsored nature of the survey (Gfroerer et al., 1997; Johnson and Fendrich, 2005). However, the NSDUH survey uses ACASI technology to encourage reporting of these behaviors directly to a computer rather than via an in-person interviewer. Self-report bias may also change over time, as attitudes of the general public towards marijuana use have become more permissive (Grucza et al., 2016). However, the increases over time in self-reported marijuana use are consistent with other studies also showing increases over time in marijuana-related outcomes that did not rely on self-report, supporting the validity of the present findings (Hasin and Grant, 2016). Second, marijuana use may predict unemployment and income loss (Henkel, 2011), invoking the possibility of reverse causation in the associations. However, this possibility is lessened because we report associations in the context of nationwide macroeconomic trends, rather than individual level changes in household income.

\section{Conclusion}

The prevalence of marijuana use increased for both men and women between 2002 and 2014 in the U.S. The gender gap in marijuana use also widened between 2007 and 2014, driven largely by increased past-year marijuana use among low income men, relative to their female counterparts. This correlates with macroeconomic changes and a persistently weak economy, especially for individ- 
uals with low socioeconomic status. As these patterns are only associations, research is needed to track individual changes in marijuana use over time in response to personal financial fluctuations, and how this may vary between men and women. Our findings suggest that national economic trends may affect substance use patterns at the population level. Discussions about U.S. economy policy, economic opportunity, income inequality, and training for low income workers should consider the possible behavioral health effects of policy change, including prevalence of marijuana use in certain segments of the population. Additionally, recognizing times of economic downturn as particularly high risk periods for low income men can help target screening and prevention efforts focused on substance use in primary care settings. Identifying income as a risk factor in gendered patterns of substance use is an important contribution to public health and harm reduction approaches, given that income is a varying and modifiable risk factor which could be targeted.

As marijuana use becomes legal in more parts of the U.S. and attitudes towards use become more permissive, gendered patterns of use could change in the future. Researchers should continue to monitor prevalence of use at a national level and use this evidence to help explain changing patterns in substance use disorders, injury morbidity and mortality, and use of other substances. National trends in marijuana use and analyses stratified by sociodemographic subgroups should continue to be monitored, in order to predict future trends in use that may inform service provision and targeted education campaigns.

\section{Role of funding source}

Supported in part by National Institute of Health grants T32DA031099 (Carliner, Mauro, Brown, PI: Hasin), R01DA037866 (Martins), R01DA034244 (Hasin), New York State Psychiatric Institute (Rahim, Sarvet, Wall, Hasin), and the Columbia University Mailman School of Public Health Department of Epidemiology (Martins, Hasin). The funders had no role in the design and conduct of the study; collection, management, analysis, and interpretation of the data; preparation, review, or approval of the manuscript; or decision to submit the manuscript for publication.

\section{Contributors}

HC, DS, MMW, and DSH are responsible for the conceptual development of this study. DS, RR, ALS, and MMW are responsible for analysis and presentation of the data. All authors contributed to the interpretation of results, read the manuscript, and approved its submission to the journal of Drug and Alcohol Dependence.

\section{Conflict of interest}

No conflict declared.

\section{Appendix A. Supplementary data}

Supplementary data associated with this article can be found, in the online version, at http://dx.doi.org/10.1016/j.drugalcdep.2016. 10.042 .

\section{References}

Acs, G., 2011. Downward Mobility From The Middle Class: Waking Up From The American Dream. Economic Mobility Project. Pew Charitable Trusts, Washington, DC

Anderson, M.D., Hansen, B., Rees, D.I., 2013. Medical marijuana laws, traffic fatalities, and alcohol consumption. J. Law Econ. 56, 333-369.
Arcaya, M., Glymour, M.M., Christakis, N.A., Kawachi, I., Subramanian, S.V., 2014. Individual and spousal unemployment as predictors of smoking and drinking behavior. Soc. Sci. Med. (1982) 110, 89-95.

Arkes, J., 2007. Does the economy affect teenage substance use? Health Econ. 16, 19-36.

Bachhuber, M.A., Saloner, B., Cunningham, C.O., Barry, C.L., 2014. Medical cannabis laws and opioid analgesic overdose mortality in the United States, 1999-2010. JAMA Int. Med. 174, 1668-1673.

Bieler, G.S., Brown, G.G., Williams, R.L., Brogan, D.J., 2010. Estimating model-adjusted risks, risk differences, and risk ratios from complex survey data. Am. J. Epidemiol. 171, 618-623.

Bor, J., Basu, S., Coutts, A., McKee, M., Stuckler, D., 2013. Alcohol use during the great recession of 2008-2009. Alcohol. 48, 343-348.

Brainerd, E., Cutler, D.M., 2004. Autopsy On An Empire: Understanding Mortality In Russia And The Former Soviet Union. National Bureau of Economic Research, Cambridge, MA.

Buckner, J.D., Bonn-Miller, M.O., Zvolensky, M.J., Schmidt, N.B., 2007. Marijuana use motives and social anxiety among marijuana-using young adults. Addict. Behav. 32, 2238-2252.

Budney, A.J., Sargent, J.D., Lee, D.C., 2015. Vaping cannabis (marijuana): parallel concerns to e-cigs? Addiction 110, 1699-1704

Bujarski, S.J., Norberg, M.M., Copeland, J., 2012. The association between distress tolerance and cannabis use-related problems: the mediating and moderating roles of coping motives and gender. Addict. Behav. 37, 1181-1184.

Business Cycle Dating Committee of the National Bureau of Economic Research, 2008. Determination of the December 2007 Peak in Economic Activity (http:// www.nber.org/cycles/dec2008.html. accessed on 3 February 2016 >).

Byrnes, J.P., Miller, D.C., Schafer, W.D., 1999. Gender differences in risk taking: a meta-analysis. Psychol. Bull. 125, 367.

CBHSQ 2015. Behavioral Health Trends in the United States: Results from the 2014 National Survey on Drug Use and Health Center for Behavioral Health Statistics and Quality. Substance Abuse and Mental Health Services Administration.

Case, A., Deaton, A., 2015. Rising morbidity and mortality in midlife among white non-Hispanic Americans in the 21 st century. Proc. Natl. Acad. Sci. 112, 15078-15083.

Catalano, R., Dooley, D., Wilson, G., Hough, R., 1993. Job loss and alcohol abuse: a test using data from the Epidemiologic Catchment Area project. J. Health Soc. Behav. 34, 215-225.

Catalano, R., Goldman-Mellor, S., Saxton, K., Margerison-Zilko, C., Subbaraman, M., LeWinn, K., Anderson, E., 2011. The health effects of economic decline. Annu. Rev. Public Health 32, 431-450.

Cerdá, M., Wall, M., Keyes, K.M., Galea, S., Hasin, D., 2012. Medical marijuana laws in 50 states: investigating the relationship between state legalization of medical marijuana and marijuana use: abuse and dependence. Drug Alcohol Depend. 120, 22-27.

Cinamon, R., 2002. Gender differences in the importance of work and family roles: implications for work-family conflict. Sex Roles 47, 531-541.

Compton, W.M., Han, B., Jones, C.M., Blanco, C., Hughes, A., 2016a. Marijuana use and use disorders in adults in the USA, 2002-14: analysis of annual cross-sectional surveys. Lancet Psychiatry 3, 954-964.

Compton, W.M., Jones, C.M., Baldwin, G.T., 2016b. Relationship between nonmedical prescription-opioid use and heroin use. N. Engl. J. Med. 374, 154-163.

Crost, B., Guerrero, S., 2012. The effect of alcohol availability on marijuana use: evidence from the minimum legal drinking age. J. Health Econ. 31, 112-121.

Ertel, J.E., Fowlkes, E.B., 1976. Some algorithms for linear spline and piecewise multiple linear regression. J. Am. Stat. Assoc. 71, 640-648.

Evangelist, M., Bernhardt, A., 2014. The Low-Wage Recovery: Industry Employment and Wages Four Years into the Recovery. National Employment Law Project, New York, NY.

Fergusson, D.M., Boden, J.M., 2008. Cannabis use and later life outcomes. Addiction 103, 969-976

Ford, M.T., 2007. Work and family satisfaction and conflict: a meta-analysis of cross-domain relations. J. Appl. Psychol. 92, 57-80.

Forret, M.L., Sullivan, S.E., Mainiero, L.A., 2010. Gender role differences in reactions to unemployment: exploring psychological mobility and boundaryless careers. J. Organ. Behav. 31, 647-666.

Gfroerer, J., Lessler, J., Parsley, T., 1997. Studies of non-response and measurement error in the National Household Survey on Drug Abuse. NIDA Res. Monogr. 167, 273-295.

Greenstone, M., Looney, A., 2011a. Have Earnings Actually Declined? Brookings Institution, Washington DC (March 4).

Greenstone, M., Looney, A., 2011b. Trends: Men in Trouble Milken Institute Review Third Quarter 2011.

Greenstone, M., Looney, A., 2013. The Lasting Effects Of The Great Recession: Six Million Missing Workers And A New Economic Normal. The Hamilton Project, Washington.

Grucza, R.A., Agrawal, A., Krauss, M.J., Cavazos-Rehg, P.A., Bierut, L.J., 2016. Recent trends in the prevalence of marijuana use and associated disorders in the United States. JAMA Psychiatry 73, 300-301.

Guttmannova, K., Lee, C.M., Kilmer, J.R., Fleming, C.B., Rhew, I.C., Kosterman, R. Larimer, M.E., 2016. Impacts of changing marijuana policies on alcohol use in the United States. Alcohol. Clin. Exp. Res. 40, 33-46.

Hall, W., Degenhardt, L., 2009. Adverse health effects of non-medical cannabis use. Lancet 374, 1383-1391. 
Hall, W., 2009. The adverse health effects of cannabis use: what are they, and what are their implications for policy? Int. J. Drug Policy 20, 458-466.

Hanson, M.D., Chen, E., 2007. Socioeconomic status and health behaviors in adolescence: a review of the literature. J. Behav. Med. 30, 263-285.

Hasin, D.S., Grant, B., 2016. NESARC findings on increased prevalence of marijuana use disorders-consistent with other sources of information. JAMA Psychiatry 73, 532-532.

Hasin, D.S., Saha, T.D., Kerridge, B.T., Goldstein, R.B., Chou, S.P., Zhang, H., Jung, J., Pickering, R.P., Ruan, W.J., Smith, S.M., Huang, B., Grant, B.F., 2015. Prevalence of marijuana use disorders in the United States between 2001 and 2002 and 2012-2013. JAMA Psychiatry 72, 1235-1242.

Hasin, D.S., Kerridge, B.T., Saha, T.D., Huang, B., Pickering, R., Smith, S.M., Jung, J., Zhang, H., Grant, B.F., 2016. Prevalence and correlates of DSM-5 cannabis use disorder, 2012-2013: findings from the national epidemiologic survey on alcohol and related conditions-III. Am. J. Psychiatry, 173.

Henkel, D., 2011. Unemployment and substance use: a review of the literature (1990-2010). Curr. Drug Abuse Rev. 4, 4-27.

Higgins, S.T., Kurti, A.N., Redner, R., White, T.J., Gaalema, D.E., Roberts, M.E., Doogan, N.J., Tidey, J.W., Miller, M.E., Stanton, C.A., 2015. A literature review on prevalence of gender differences and intersections with other vulnerabilities to tobacco use in the United States 2004-2014. Prev. Med. 80, 89-100.

Johnson, T., Fendrich, M., 2005. Modeling sources of self-report bias in a survey of drug use epidemiology. Ann. Epidemiol. 15, 381-389.

Kearney, M.S., Hershbein, B., Jácome, E., 2015. Profiles Of Change: Employment, Earnings, And Occupations From 1990-2013. The Hamilton Project at the Brookings Institute, Washington, DC.

Kerr, W.C., Greenfield, T.K., Bond, J., Ye, Y., Rehm, J., 2007. Age-period-cohort influences on trends in past year marijuana use in the US from the 1984, 1990, 1995 and National Alcohol Surveys. Drug Alcohol Depend. 86, 132-138.

Keyes, K.M., Grant, B.F., Hasin, D.S., 2008. Evidence for a closing gender gap in alcohol use, abuse, and dependence in the United States population. Drug Alcohol Depend. 93, 21-29.

Keyes, K.M., Li, G., Hasin, D.S., 2011. Birth cohort effects and gender differences in alcohol epidemiology: a review and synthesis. Alcohol. Clin. Exp. Res. 35, 2101-2112.

Kim, J.H., Santaella, J., Cerda, M., Martins, S.S., 2015. Medical marijuana laws and annual opioid analgesic sales in the United States. Drug Alcohol Depend. 156, e111.

Kim, J.H., Santaella-Tenorio, J., Mauro, C., Wrobel, J., Cerdà, M., Keyes, K.M., Hasin, D., Martins, S.S., Li, G., 2016. State medical marijuana laws and the prevalence of opioids detected among fatally injured drivers. Am. J. Public Health 106, 2032-2037.

Lee, D.C., Crosier, B.S., Borodovsky, J.T., Sargent, J.D., Budney, A.J., 2016. Online survey characterizing vaporizer use among cannabis users. Drug Alcohol Depend. 159, 227-233.

Li, M.-C., Brady, J.E., DiMaggio, C.J., Lusardi, A.R., Tzong, K.Y., Li, G., 2012. Marijuana use and motor vehicle crashes. Epidemiol. Rev. 34, 65-72.

MacCoun, R., Pacula, R.L., Chriqui, J., Harris, K., Reuter, P., 2009. Do citizens know whether their state has decriminalized marijuana?: Assessing the perceptual component of deterrence theory. Rev. Law Econ. 5, 347-371.

Martins, S.S., Mauro, C., Santaella, J., Kim, J.H., Cerda, M., Keyes, K.M., Hasin, D.S. Galea, S., Wall, M.M., 2016. State-level medical marijuana laws: marijuana use and perceived availability of marijuana use among the general U.S. population. Drug Alcohol Depend. 169, 26-32.

Maxwell, J.C., Mendelson, B., 2016. What do we know now about the impact of the laws related to marijuana? J. Addict. Med. 10, 3-12.

McHugh, R.K., Wigderson, S., Greenfield, S.F., 2014. Epidemiology of substance use in reproductive-age women. Obstet. Gynecol. Clin. North Am. 41, 177-189.

McKee-Ryan, F., Song, Z., Wanberg, C.R., Kinicki, A.J., 2005. Psychological and physical well-being during unemployment: a meta-analytic study. J. Appl. Psychol. 90, 53.

Meara, E., Skinner, J., 2015. Losing ground at midlife in America. Proc. Natl. Acad. Sci. 112, 15006-15007

Meiman, J., Tomasallo, C., Paulozzi, L., 2015. Trends and characteristics of heroin overdoses in Wisconsin, 2003-2012. Drug Alcohol Depend. 152, 177-184.

Merline, A.C., O'malley, P.M., Schulenberg, J.E., Bachman, J.G., Johnston, L.D., 2004. Substance use among adults 35 years of age: prevalence, adulthood predictors, and impact of adolescent substance use. Am. J. Public Health 94, 96-102.

Miller, D.S., Miller, T.Q., 1997. A test of socioeconomic status as a predictor of initial marijuana use. Addict. Behav. 22, 479-489.

Moos, R.H., 2007. Theory-based active ingredients of effective treatments for substance use disorders. Drug Alcohol Depend. 88, 109-121.

Mossakowski, K.N., 2008. Is the duration of poverty and unemployment a risk factor for heavy drinking? Soc. Sci. Med. 67, 947-955.

Muggeo, V.M., 2003. Estimating regression models with unknown break-points. Stat. Med. 22, 3055-3071.
Noel, J.K., Rees, V.W., Connolly, G.N., 2011. Electronic cigarettes: a new 'tobacco' industry? Tob. Control 20, 81.

Pacek, L.R., Mauro, P.M., Martins, S.S., 2015. Perceived risk of regular cannabis use in the United States from 2002 to 2012: differences by sex, age, and race/ethnicity. Drug Alcohol Depend. 149, 232-244.

Pacula, R.L., Powell, D., Heaton, P., Sevigny, E.L., 2013. Assessing The Effects Of Medical Marijuana Laws On Marijuana And Alcohol Use: The Devil Is In The Details. National Bureau of Economic Research, Cambridge, MA.

Pew Research Center, 2014. America's Changing Drug Policy Landscape. Pew Research Center, Washington, DC.

Pitel, L., Madarasová Gecková, A., Reijneveld, S.A., van Dijk, J.P., 2013. Socioeconomic differences in adolescent health-related behavior differ by gender. J. Epidemiol. 23, 211-218

Powell, D., Pacula, R.L., Jacobson, M., 2015. Do Medical Marijuana Laws Reduce Addictions and Deaths Related to Pain Killers? National Bureau of Economic Research, Cambridge, MA.

ProCon.org, 2016. 28 Legal Medical Marijuana States and DC, accessed on 16 November 2016 http://medicalmarijuana.procon.org/view.resource. php?resourceID=000881.

Ronay, R., Kim, D.-Y., 2006. Gender differences in explicit and implicit risk attitudes: a socially facilitated phenomenon. Br. J. Soc. Psychol. 45, 397-419.

Rothman, K.J., Greenland, S., Lash, T.L., 2008. Modern Epidemiology. Lippincott Williams \& Wilkins, New York.

SAMHSA, 2003. Results from the 2002 National Survey on Drug Use and Health. National Findings Substance Abuse and Mental Health Services Administration, Rockville, MD.

SAMHSA, 2014. Results from the 2013 National Survey on Drug Use and Health. Summary of National Findings. Substance Abuse and Mental Health Services Administration, Rockville, MD.

Schmitt, J., Jones, J., 2012. Where Have All the Good Jobs Gone? Center for Economic and Policy Research, Washington, DC.

Schwarz, C.J., 2015. Regression - hockey sticks, broken sticks, piecewise, change points. Course Notes Begin.Intermed. Stat.

Seefeldt, K., Abner, G., Bolinger, J.A., Xu, L., Graham, J.D., 2012. At Risk: America's Poor During And After The Great Recession. Indiana University School of Public and Environmental Affairs, Bloomington, IN.

Sherman, J., 2009. Bend to avoid breaking: job loss, gender norms, and family stability in rural America. Soc. Probl. 56, 599-620.

Simons, J., Correia, C.J., Carey, K.B., 2000. A comparison of motives for marijuana and alcohol use among experienced users. Addict. Behav. 25, 153-160.

Stinson, F.S., Ruan, W.J., Pickering, R., Grant, B.F., 2006. Cannabis use disorders in the USA: prevalence, correlates and co-morbidity. Psychol. Med. 36, $1447-1460$.

Substance Abuse and Mental Health Services Administration, 2003. Results from the 2002 National Survey on Drug Use and Health: National Findings. Office of Applied Studies, Rockville, MD.

Substance Abuse and Mental Health Services Administration, 2014. Results from the 2013 National Survey on Drug Use and Health: Summary of National Findings. Substance Abuse and Mental Health Services Administration, Rockville, MD.

Tashkin, D.P., Baldwin, G.C., Sarafian, T., Dubinett, S., Roth, M.D., 2002. Respiratory and immunologic consequences of marijuana smoking. J. Clin. Pharmacol. 42, $71 \mathrm{~S}-81 \mathrm{~S}$.

Taylor, S.E., Stanton, A.L., 2007. Coping resources, coping processes, and mental health. Annu. Rev. Clin. Psychol. 3, 377-401.

Tekin, E., McClellan, C., Minyard, K.J., 2013. Health and Health Behaviors During The Worst Of Times: Evidence From The Great Recession. National Bureau of Economic Research, Cambridge, MA.

Toms, J.D., Lesperance, M.L., 2003. Piecewise regression: a tool for identifying ecological thresholds. Ecology 84, 2034-2041.

2016. Labor Force Statistics from the Current Population Survey: Employment-Population Ratio. U.S. Bureau of Labor Statistics, Washington, DC.

2010. Resident Population Data. U.S. Census Bureau, Washington, DC.

Vijayasiri, G., Richman, J.A., Rospenda, K.M., 2012. The Great Recession, somatic symptomatology and alcohol use and abuse. Addict. Behav. 37, 1019-1024.

Volkow, N.D., Baler, R.D., Compton, W.M., Weiss, S.R.B., 2014. Adverse health effects of marijuana use. N. Engl. J. Med. 370, 2219-2227.

Wen, H., Hockenberry, J., Cummings, J.R., 2014. The Effect Of Medical Marijuana Laws On Marijuana, Alcohol, And Hard Drug Use. National Bureau of Economic Research, Cambridge, MA

White, A., Castle, I.J.P., Chen, C.M., Shirley, M., Roach, D., Hingson, R., 2015. Converging patterns of alcohol use and related outcomes among females and males in the United States, 2002 to 2012. Alcohol. Clin. Exp. Res. 39, $1712-1726$.

Wills, T.A., Shiffman, S., 1985. Coping and substance use: a conceptual framework. Cop. Subst. Use, 3-24. 